\title{
IMPLEMENTASI PERAMALAN DOUBLE EXPONENTIAL SMOOTHING PADA KASUS KEKERASAN ANAK DI PUSAT PELAYANAN TERPADU PEMBERDAYAAN PEREMPUAN DAN ANAK
}

\author{
${\text { Riyadhul Fajri }{ }^{1} \text {, Teuku Muhammad Johan }}^{2}$ \\ ${ }^{1,2}$ Program Studi Teknik Informatika, Fakultas Ilmu Komputer, Universitas Almuslim, Bireuen - Aceh \\ Email : fajri071113@gmail.com, johantm@yahoo.com
}

\begin{abstract}
The high number of cases of violence in children today is increasing. Among the cases of child abuse are physical torture, sexual harassment and neglect. Every year violence in children increases with different patterns of behavior. Various efforts were made by the government to campaign for child protection legislation. To forecast an increase or decrease in child abuse patterns over the next 5 years, an inhalamanation-based forecasting system is needed. This inhalamanation system is expected to predict how many cases of child abuse that occur from the time in the future. Double expoential smoothing method is the most widely used method to determine the equation of second smoothing data trend through smoothing process. This forecasting system captures the pattern of past data then used to project future data. The purpose of this system is to provide an idea of the level of violence in children. The variables used in this system are the types of cases of domestic violence / Traumatic cases of Persecution, Kidnapping cases, Rape cases and Sodomy case types. The case of violence predicted for four years previous year is in 2012, 2013, 2014, 2015. Then processed using the method of double expnential smoothing by looking for the equation of the trend first and followed by looking for second smoothing and forecasting results of the type of violence in the next year that is 2016.

The special target of this forecasting system is to project a pattern of child abuse that is still frequent and predict patterns of violence in children for the next few years. This is done to prepare everything needed to handle cases of violence in the future. Long-term goal to predict the level of violence in children for the next 10 years. This is expected to anticipate the acts of violence that occur in children by looking at previous forecasting data.
\end{abstract}

Keywords: Double Exponential Smoothing, Forecasting, Type of Child Violence

\section{INTISARI}

Tingginya kasus kekerasan pada anak dewasa ini semakin meningkat. Diantara kasus kekerasan pada anak yaitu penyiksaan fisik, pelecehan seksual, dan penelantaran. Setiap tahun kekerasan pada anak semakin meningkat dengan pola perilaku yang berbeda-beda. Berbagai upaya dilakukan pemerintah untuk mengkampanyekan undang-undang perlindungan anak. Untuk meramalkan meningkat atau menurunnya pola kekerasan pada anak selama 5 tahun mendatang dibutuhkan sebuah peramalan berbasis system inhalamanasi. Sistem inhalamanasi ini diharapkan dapat meramalkan seberapa banyak kasus kekerasan anak yang terjadi dari waktu pada masa yang akan datang. Metode Double expoential smoothing adalah suatu metode yang paling luas digunakan untuk menentukan persamaan trend data pemulusan kedua melalui proses smoothing. Sistem peramalan ini menangkap pola dari data yang telah lalu kemudian digunakan untuk memproyeksikan data yang akan datang. Tujuan dari sistem ini adalah untuk memberikan gambaran tingkat kekerasan pada anak. Variabel yang digunakan pada sistem ini adalah jenis kasus KDRT/Traumatis kasus Penganiayaan, kasus Penculikan, kasus Perkosaan dan Jenis kasus Sodomi. Kasus kekerasan yang diramalkan selama empat tahun tahun sebelumnya yaitu tahun 2012, 2013, 2014, 2015. Kemudian diproses menggunakan metode Double expnential smoothing dengan mencari persamaan trend terlebih dahulu dan dilanjutkan dengan mencari pemulusan kedua dan hasil peramalan yaitu jenis kekerasan pada tahun berikutnya yaitu 2016.

Target Khusus dari system peramalan ini adalah untuk memproyeksikan pola kekerasan pada anak yang masih sering dan memprediksikan pola kekerasan pada anak untuk beberapa tahun kedepan. Hal ini dilakukan untuk mempersiapkan segala hal yang dibutuhkan untuk menangani kasus kekerasan pada masa yang mendatang. Tujuan jangka panjang untuk dapat memprediksikan tingkat kekerasan pada anak untuk masa 10 tahun kedepan. Hal ini diharapkan dapat mengantisipasi tindak kekerasan yang terjadi pada anak dengan melihat data peramalan sebelumnya.

Kata Kunci : Double exponential Smoothing, Jenis Kekerasan Anak, Peramalan 


\section{PENDAHULUAN}

Anak adalah tumpuan dan harapan orang tua. Anak jugalah yang akan menjadi penerus bangsa ini. Sedianya, wajib dilindungi maupun diberikan kasih sayang. Namun fakta berbicara lain. Maraknya kasus kekerasan pada anak sejak beberapa tahun ini seolah membalikkan pendapat bahwa anak perlu dilindungi. Begitu banyak anak yang menjadi korban kekerasan keluarga, lingkungan maupun masyarakat dewasa ini. Pasal 28 b ayat 2 menyatakan bahwa "Setiap anak berhak atas kelangsungan hidup, tumbuh, dan berkembang serta berhak atas perlindungan dari kekerasan dan diskriminas".

Tingkat kekerasan terhadap anak di Indonesia masih tergolong tinggi. Komisi Perlindungan Anak Indonesia (KPAI) saat ini mencatat ada 1000 kasus kekerasan pada anak dalam kurun waktu selama tahun 2016. Jumlahnya bisa meningkat karena ada yang laporan di Polri dan jajarannya dan banyak dari pelaku kekerasan terhadap anak ini justru adalah orang tua dari anak itu sendiri. David Gill (dalam Sudaryono, 2007) mengartikan perlakuan salah terhadap anak adalah termasuk penganiayaan, penelantaran dan ekspoitasi terhadap anak, dimana hal ini adalah hasil dari perilaku manusia yang keliru terhadap anak. Bentuk kekerasan terhadap anak tentunya tidak hanya berupa kekerasan fisik saja, seperti penganiayaan, pembunuhan, maupun perkosaan, melainkan juga kekerasan non fisik, seperti kekerasan ekonomi, psikis, maupun kekerasan religi.

Kekerasan ini bisa terjadi kapan saja dan dimana saja tak terkecuali di wilayah aceh utara sehingga pihak keamanan atau psikologi harus selalu siap untuk menangani setiap kriminalitas yang terjadi khususnya para polisi yang bertugas di satuan reserse kriminal. Oleh karena itu satuan reserse kriminal harus bisa memperhitungkan segala hal mengenai tindak kriminal yang sudah terjadi, sedang terjadi dan yang mungkin akan terjadi agar bisa menanganinya dengan tepat guna memberikan rasa aman bagi masyarakat di wilayah hukumnya. Misalkan saja salah satu kesiapan satuan reserse kriminal yaitu dapat memperhitungkan tingkat jumlah krimanal yang akan terjadi berikutnya, sehingga satuan reserse kriminal dapat mempersiapkan segala hal untuk menanganinya seperti mempersiapkan jumlah personil yang diperlukan, senjata atau perlengkapan lainnya guna mengatasi tindak kriminal di wilayah hukumnya masing-masing, dan juga melakukan pencegahan sedini mungkin guna meminimalisir tingkat jumlah tindak kriminal sehingga memberikan rasa aman bagi masyarakat.

Kemampuan komputer sebagai perangkat yang membantu untuk mempermudah tugas atau kerja seseorang menjadi lebih mudah, lebih efektif dan lebih efisien khususnya dalam kecepatan proses dan keakuratan hasil yang diberikan diharapkan dapat membantu untuk mempermudah dalam peramalan kasus kekerasan anak dengan menggunakan metode double exponential smoothing.

Selama ini, peramalan kasus kekerasan anak belum dapat di lakukan karena sistem inhalamanasi yang tidak mendukung. Oleh karena itu dibutuhkan sebuah sistem yang dapat meramalkan seberapa banyak kasus kekerasan anak yang terjadi dari waktu ke waktu. Penyediaan sistem peramalan kekerasan anak yang menggunakan Tools apliaksi menggunakan sistem pendukung keputusan memungkinkan peramalan data kekerasan anak.

Dalam situasi seperti ini pentingnya peramalan untuk menyelesaikan masalah mengenai data-data masa lampau yang dapat diolah untuk membantu dalam pengambilan keputusan di masa yang akan datang. Dengan penerapan suatu teori peramalan dalam melihat kasus kekerasan, akan sangat membantu meningkatkan peluang keuntungan yang lebih tinggi di masa akan datang. Proses peramalan metode tersebut menangkap pola dari data yang telah lalu kemudian digunakan untuk memproyeksikan data yang akan datang. Variabel data yang di input adalah jenis-jenis kekerasan pada masa lampau dan kemudian di proses dalam trend data, Selanjutnya tahap hasil peramalan menggunakan metode double exponential smooting adalah hasil alpha dengan nilai error paling minimum yang paling baik untuk melihat jenis-jenis kekerasan yang paling sedikit.

\section{DASAR TEORI}

\section{A. Peramalan}

Peramalan merupakan suatu usaha untuk meramalkan keadaan di masa mendatang melalui 
pengujian keadaan dimasa lalu. Esensi peramalan adalah perkiraan peristiwa-peristiwa di waktu yang akan datang atas dasar pola-pola di waktu yang lalu, dan penggunaan kebijakan terhadap proyeksi-proyeksi dengan pola-pola di waktu yang lalu. Peramalan adalah seni dan ilmu untuk memperkirakan kejadian di masa depan. Hal ini dapat dilakukan dengan melibatkan pengambilan data masa lalu dan menempatkannya ke masa yang akan datang dengan suatu bentuk model matematis [5].

Peramalan adalah suatu taksiran atau perkiraan nilai-nilai sebuah variable berdasarkan kepada nilai yang diketahui dari variable tersebut atau variable yang berhubungan dengan bantuan perhitungan statistik dalam memperoleh gambaran kejadian dimasa mendatang [4].

Peramalan adalah suatu proses memperkirakan secara sistematis tentang apa yang mungkin terjadi dimasa yang akan datang berdasarkan inhalamanasi masa lalu dan sekarang yang dimiliki agar kesalahannya dapat diperkecil. Peramalan tidak memberikan jawaban pasti tentang apa yang akan terjadi, melainkan berusaha mencari pendekatan tentang apa yang terjadi sehingga dapat memberikan kontribusi dalam menentukan keputusan yang terbaik.

\section{B. Tujuan Peramalan}

Tujuan peramalan adalah mendapatkan peramalan yang bisa meminimumkan kesalahan meramal (forecast error) yang bisa diukur dengan Mean Absolute Deviation (MAD) dan Mean Square Error (MSE). Sehingga dengan adanya peramalan produksi manajemen perusahaan akan mendapatkan gambaran keadaan produksi dimasa yang akan datang, dan akan memberikan kemudahan manajemen perusahaan dalam menentukan kebijakan yang akan dibuat oleh perusahaan. Tujuan peramalan yang lain adalah untuk meramalkan permintaan dari item-item independent demand dimasa yang akan datang [3].

\section{Horizon Waktu Dalam Peramalan}

Peramalan biasanya di klasifikasikan berdasarkan horizon waktu masa depan yang terbagi atas beberapa kategori :

1. Peramalan Jangka Pendek
Peramalan ini mencakup jangka waktu hingga satu tahun, tetapi umumnya kurang dari tiga bulan. Peramalan ini digunakan untuk merencanakan pembelian, penjadwalan kerja, jumlah tenaga kerja, penugasan kerja dan tingkat produksi.

2. Peramalan Jangka Menengah

Peramalan ini umumnya mencakup hitungan bulanan hingga tiga tahun. Peramalan ini digunakan untuk merencanakan penjualan, perencanaan dan anggaran produksi, anggaran kas, dan menganalisis bermacam-macam rencana operasi.

3. Peramalan Jangka Panjang

Peramalan ini umumnya untuk perencanaan masa tiga tahun atau lebih. Peramalan ini digunakan untuk merencanakan produksi baru, pembelanjaan modal, lokasi atau pengembangan fasilitas, serta penelitian dan pengembangan.

\section{Metode Single Exponential Smoothing}

Penghalusan exponential adalah teknik peramalan rata-rata bergerak dengan pembobotan dimana data diberi bobot oleh sebuah fungsi exponential. Penghalusan exponential merupakan metode peramalan ratarata bergerak dengan pembobotan canggih, namun masih mudah digunakan. Metode ini sangat sedikit pencatatan data masa lalu [3].

Rumus untuk Single Exponential Smoothing adalah sebagai berikut :

$$
F_{t+1}=\alpha X_{t}+(1-\alpha) F_{t-1}
$$

\section{keterangan :}

$\mathrm{F}_{\mathrm{t}+1} \quad=$ Ramalan untuk periode ke $\mathrm{t}+1$

$\alpha \quad=$ Bobot yang menunjukkan konstanta penghalus $(0<\alpha<1)$

$\mathrm{X}_{\mathrm{t}} \quad=$ Nilai riil periode ke $\mathrm{t}$

$\mathrm{F}_{\mathrm{t}-1}=$ Ramalan untuk periode ke $\mathrm{t}-1$

Metode ini membutuhkan nilai alpha $(\alpha)$ sebagai nilai parameter pemulusan. Bobot nilai $\alpha$ lebih tinggi di berikan kepada data yang lebih baru, sehinggan nilai parameter $\alpha$ yang sesuai akan memberikan ramalan yang optimal dengan nilai kesalahan (error) terkecil. Untuk mendapatkan nilai $\alpha$ yang tepat pada umumnya dilakukan dengan trial and error (coba-coba 
tingkat kepastian dalam meramal) untuk menentukan nilai kesalahan terendah.

\section{E. Metode Double Exponential Smoothing}

Dasar pemikiran dari metode exponential smoothing tunggal maupun ganda adalah bahwa nilai pemulusan akan terdapat pada waktu sebelum data sebenarnya apabila pada data tersebut terdapat komponen trend. Oleh karena itu untuk nilai-nilai pemulusan tunggal perlu di tambahkan nilai pemulusan ganda untuk menyesuaikan trend. Metode exponential smoothing ganda yang dapat digunakan untuk menyelesaikan trend linier adalah metode dua parameter dari Holt. Pada metode Holt nilai trend tidak di muluskan dengan pemulusan ganda secara langsung, tetapi proses pemulusan trend dilakukan dengan menggunakan parameter yang berbeda dengan parameter yang digunakan pada pemulusan data asli. Metode Double Exponential Smoothing digunakan ketika data menunjukkan adanya trend [1].

Rumus Double Exponential Smoothing dapat ditunjukkan sebagai berikut :

$$
\begin{aligned}
& \mathrm{S}_{\mathrm{t}}=\alpha \mathrm{X}_{\mathrm{t}}+(1-\alpha)\left(\mathrm{S}_{\mathrm{t}-1}+\mathrm{T}_{\mathrm{t}-1}\right) \\
& \mathrm{T}_{\mathrm{t}}=\beta\left(\mathrm{S}_{\mathrm{t}}-\mathrm{S}_{\mathrm{t}-1}\right)+(1-\beta) \mathrm{T}_{\mathrm{t}-1} \\
& \mathrm{~F}_{\mathrm{t}+\mathrm{m}}=\mathrm{S}_{\mathrm{t}}+\mathrm{T}_{\mathrm{t}} . \mathrm{m}
\end{aligned}
$$

\section{keterangan :}

$\mathrm{St}=$ Nilai pemulusan tunggal

$\mathrm{Xt}=$ Data sebenarnya pada waktu ke $\mathrm{t}$

$\mathrm{Tt} \quad=$ Pemulusan trend

$\mathrm{F}(\mathrm{t}+\mathrm{m})=$ Nilai ramalan

$\mathrm{m} \quad=$ Periode masa mendatang

$\alpha \quad=$ Koefisien pemulusan (smoothing) $(0<\alpha<1)$

$\beta \quad=$ Koefisien pemulusan (smoothing) untuk trend $(0<\beta<1)$

\section{F. Ukuran Kesalahan Peramalan}

Ukuran kesalahan peramalan adalah penyimpangan antara aktual demand dengan hasil peramalan. Peramalan adalah hasil taksiran kita akan suatu nilai dimasa yang akan datang, karena masih berupa taksiran maka besar kemungkinan adanya kesalahan pada peramalan. Evaluasi hasil peramalan digunakan untuk mengetahui keakuratan hasil peramalan yang telah dilakukan terhadap data yang sebenarnya.
G. Ukuran Ketepatan Peramalan dengan Mean Squred Error (MSE)

Hasil ramalan tidak selalu akurat atau sering berbeda dengan keadaan sesungguhnya (data aktual). Perbedaan antara ramalan dengan keadaan sesungguhnya disebut dengan kesalahan ramalan (forecast error). Menilai ketepatan suatu periode peramalan dapat dilakukan dengan cara mencari selisih besaran (ukuran kesalahan peramlan) data peramalan terhadap data aktual [8].

Dengan membandingkan ukuran kesalahan terkecil, sehingga nilai peramalan dapat digunakan sebagai acuan dalam menentukan kebutuhan-kebutuhan dimasa yang akan datang. Dalam statistik untuk menguji ukuran kesalahan peramalan bisa menggunakan beberapa metode. Salah satu cara yang digunakan yaitu MSE (Mean Squred Error). Mean Squred Error (MSE) merupakan suatu perhitungan jumlah dari selisih data peramalan dengan data yang sebenarnya. Pada umumnya, semakin kecil nilai MSE maka ramalan semakin akurat.

Berikut ini merupakan rumus MSE (Mean Squred Error) yaitu :

$$
\mathrm{MSE}=\frac{\sum_{t=1}^{n}(\mathrm{Xt}-\mathrm{Ft}) 2}{n}
$$

keterangan :

$$
\begin{aligned}
\mathrm{MSE}= & \text { Kesalahan peramalan MSE } \\
& \text { (Mean Squred Error }) \\
\mathrm{Xt}= & \text { Nilai aktual pada periode } \mathrm{t} \\
\mathrm{Ft} & =\text { Nilai peramalan pada periode } \mathrm{t} \\
\mathrm{n} & =\text { Banyaknya data }
\end{aligned}
$$

\section{METODE PENELITIAN}

\section{A. Pengumpulan Data}

Dalam penelitian ini data yang digunakan adalah jenis data sekunder yaitu berupa data jenis kasus kekerasan pada tahun 2013-2016 dan jenis-jenis kekerasan pada tahun 2017. Adapun langkah-langkah dalam pengumpulan data adalah sebagai berikut:

1. Metode Studi Literatur

2. Metode Observasi

3. Metode Wawancara

4. Pemeriksaan Dokumen 


\section{B. Analisa Data}

Data yang diperoleh pada penelitian ini ada dua yaitu data data kuantitatif yaitu data yang berupa angka didapatkan dari data primer dalam penelitan pada data peramalan yang akan dimasukkan kedalam metode double exponential smoothing pada jenis tindak kekerasan.

\section{Sumber Data}

Sumber data dalam penelitian ini adalah data primer yaitu Data yang diperoleh dilembaga data anak. kemudian Data berupa data kuantitatif untuk jenis kekerasan pada tahun 2013-2015. Data yang diramalkan dapat berupa data 2016.

\section{Model yang Digunakan}

Model untuk aplikasi peramalan untuk jenis kekerasan menggunakan double exponential smoothing, perancangan diagram menggunakan model Data Flow Diagram.

\section{E. Rancangan Penelitian}

Data yang diperoleh pada penelitian ini ada dua yaitu data kualitatif yaitu data yang berupa inhalamanasi dari hasil data kuantitatif yaitu data yang berupa angka didapatkan dari data primer dalam penelitan pada data peramalan yang akan dimasukkan kedalam metode Double Exponential Smoothing. Dari data tersebut dilakukan pengolahan analisis data pada langkah-langkah penelitian adalah sebagai berikut :

1. Tahap Perencanaan

Pada tahap ini Penelitian melakukan perencanaan data yang akan diramal pada tahun 2015 menggunakan metode double exponential smoothing.

2. Pengambilan data

Pada tahap ini penelitian memilih data jumlah kekerasan anak setiap tahun yang dibatasi hanya data kekerasan anak.

3. Penyusunan data

Tahap ini data yang disusun oleh Penelitian terdiri dari data tahun 2012, data tahun 2013, data tahun 2014.

4. Pembukuan data

Dari tahap ini Penelitian dapat melihat dan mengambil kesimpulan bahwa peramalan jumlah tindak kekerasan anak yang akan diramal adalah tahun 2015.

5. Tahap perancangan aplikasi
Pada tahap ini Penelitian merancang dan mendesain aplikasi basis data berupa relationship data yang dapat menghasil data yang akurat dengan menggunakan metode dekomposisi.

6. Pengujian

Pengujian dilakukan dengan mencoba secara detail pada aplikasi peramalan jenis kekerasan

7. Laporan

Pada tahap ini penelitian merancang laporan terdiri dari laporan peramalan tingkat jumlah kriminal tahun 2015, berupa laporan maupun grafik.

\section{HASIL DAN PEMBAHASAN}

\section{A. Analisa Sistem}

Kekerasan terhadap anak adalah tindak kekerasan secara fisik, seksual, penganiyaan emosional, atau pengabaian terhadap anak. Dalam penelitian ini dibahas empat kategori utama tindak kekerasan terhadap anak yaitu traumatik, kekerasan fisik, pelecehan emosional/psikologis, dan pelecehan seksual anak. Selama ini, peramalan kasus kekerasan anak belum dapat di lakukan karena sistem inhalamanasi yang tidak mendukung. Oleh karena itu dibutuhkan sebuah sistem inhalamanasi yang dapat meramalkan seberapa banyak kasus kekerasan anak yang terjadi dari waktu ke waktu dan meramalkan kondisi kondisi tersebut pada masa yang akan datang. Metode double expoential smoothing adalah suatu metode yang paling luas digunakan untuk menentukan persamaan trend data pemulusan kedua melalui proses smoothing. Sistem peramalan ini menangkap pola dari data yang telah lalu kemudian digunakan untuk memproyeksikan data yang akan datang.

\section{B. Hasil Perancangan Sistem}

Perancangan Sistem merupakan kejadian dari suatu diagram alir data, dimana satu lingkaran mempresentasikan seluruh sistem dan merupakan tingkatan tertinggi dalam diagram aliran data dan hanya memuat satu proses dan menunjukkan sistem secara keseluruhan. Diagram aliran data hanya memuat satu proses 
dan menunjukkan sistem secara keseluruhan yaitu seperti pada Gambar 1.

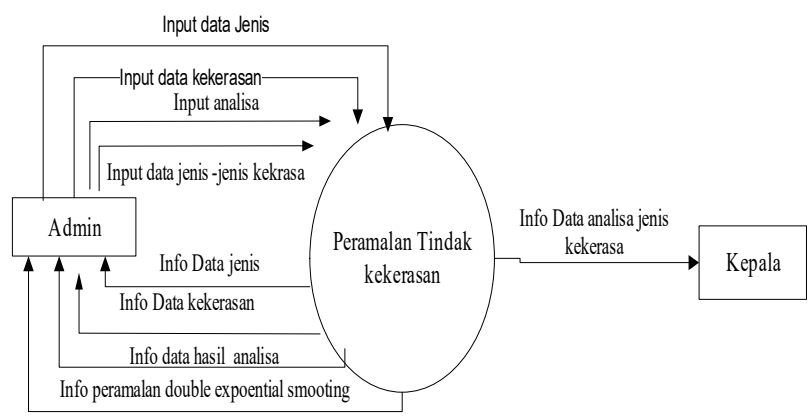

Gambar 1. Diagram Konteks

\section{Tabel Database}

1. Tabel Admin

Tabel ini berfungsi menyimpan data Admin. Tabel 1 ini terdiri dari dua field, yaitu username dan password adalah sebagai berikut:

Tabel 1. Tabel admin

\begin{tabular}{|l|l|l|l|l|}
\hline No & Field & Tipe & Size & Keterangan \\
\hline 1. & Id_User & Varchar & 15 & \\
\hline 2. & Username & Varchar & 15 & \\
\hline 3. & Password & Varchar & 15 & \\
\hline 4. & Akses & Varchar & 10 & \\
\hline
\end{tabular}

2. Tabel Total Jenis Kekerasan

Tabel 2 ini berfungsi untuk menyimpan data jenis kekerasan. Adapun tabel data adalah sebagai berikut :

Tabel 2. Tabel jenis kekerasan

\begin{tabular}{|l|c|c|c|}
\hline \multicolumn{1}{|c|}{ Nama } & Type & Ukuran & Keterangan \\
\hline jenis_id & int & 15 & \\
\hline Jeniskekerasan_id & Varchar & 15 & \\
\hline Nama_Kekerasan & Double & & \\
\hline Nama_Jenis & Varchar & 15 & \\
\hline Jenis & Varchar & 15 & \\
\hline Total_Kekerasan & int & 11 & \\
\hline
\end{tabular}

\section{Tabel Hasil Uji}

Tabel uji ramal berfungsi untuk ramalan dengan menggunakan double exponential smooting pada Implementasi Peramalan Double Exponential Smoothing pada Kasus Kekerasan
Anak. Adapun tabel uji stok dan unit entry penjualan dapat dilihat pada Tabel 3.

Tabel 3. Tabel uji peramalan

\begin{tabular}{|l|l|c|c|}
\hline \multicolumn{1}{|c|}{ Nama } & Type & Ukuran & Keterangan \\
\hline id_uji & int & 11 & \\
\hline aktual & float & & \\
\hline alpha & float & 12 & \\
\hline mape & float & 11 & \\
\hline ramalan & float & & \\
\hline
\end{tabular}

\section{Tabel Analisa}

Tabel 4 ini berfungsi untuk menyimpan data hasil analisa penilaian jenis ramalan kekersan pada anak yang dilakukan oleh pengguna aplikasi adalah sebagai berikut:

\begin{tabular}{|l|c|c|l|}
\multicolumn{1}{|c|}{ Tabel 4. Tabel analisa } \\
\hline Nama & Type & Ukuran & Keterangan \\
\hline *Id_hasil & Int & 11 & Primarykey \\
\hline Id_pengguna & Varchar & 15 & \\
\hline
\end{tabular}

\section{Implementasi Tindak Kekerasan pada Anak}

1. Halaman Login

Halaman login berfungsi untuk masuk ke program input dan laporan untuk melihat hasil ramalan. Tampilan halaman login yang terdiri dari username dan password dapat dilihat pada Gambar 2.

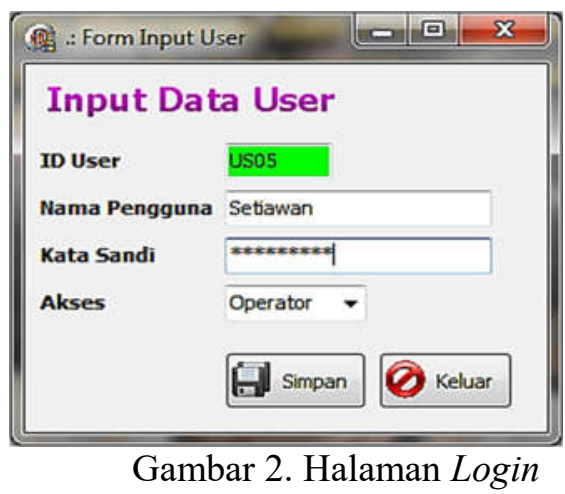

2. Halaman Utama

Halaman menu utama terdiri dari lima buah menu utama, yaitu menu file data, file menu, file proses, file cetak dan tentang aplikasi yang dijalankan. Adapun tampilan halaman menu seperti tampilan Gambar 3. 


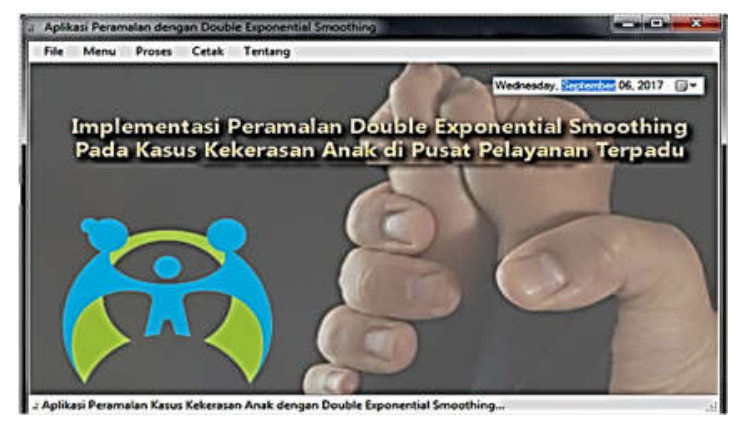

Gambar 3. Halaman Utama

\section{Halaman Menu Input}

Halaman menu input digunakan untuk mengisi data input data kekerasan. Adapun halaman menu input dapat dilihat pada Gambar 4.

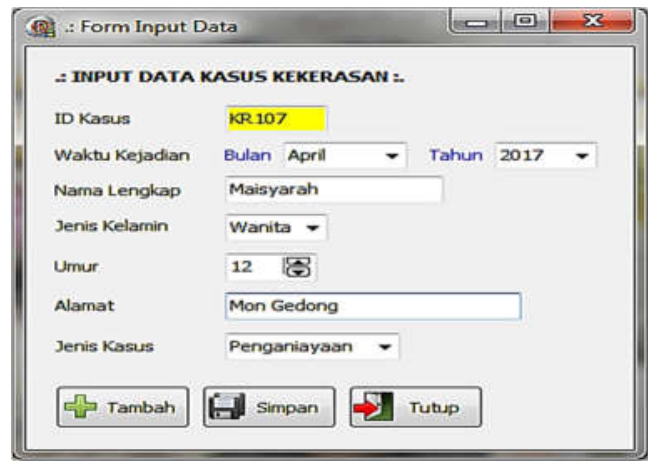

Gambar 4. Halaman menu input

\section{Halaman Lihat Data Kasus Kekerasan}

Halaman menu lihat data kasus kekerasan digunakan untuk melihat data kekerasan. Adapun halaman menu lihat data kasus kekerasan dapat dilihat pada Gambar 5.

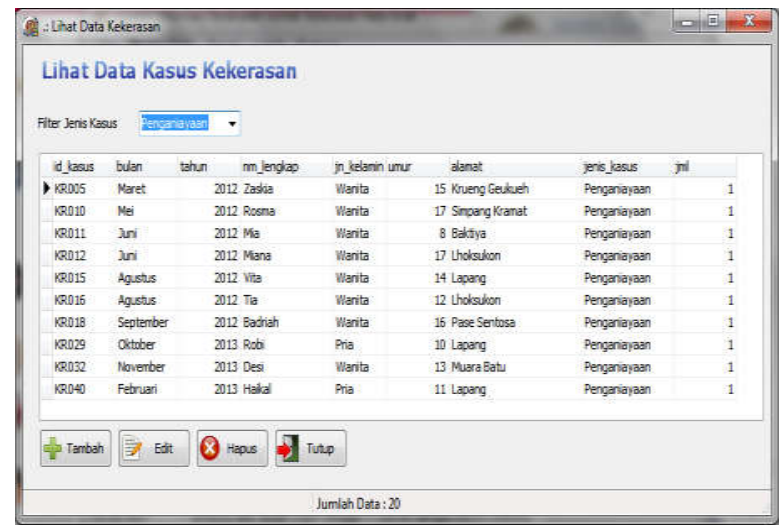

Gambar 5. Halaman lihat data kasus kekerasan

\section{Halaman Menu Lihat Jenis Kasus}

Halaman menu lihat jenis data kasus kekerasan digunakan untuk melihat data kekerasan. Adapun halaman menu input lihat jenis kasus dapat dilihat pada Gambar 6 .
Data Jenis Kasus

\begin{tabular}{|c|c|c|c|}
\hline id_jenis & jenis_kasus & $A$ & گ Tambah \\
\hline JNO1 & KDRT/Traumatis & \multirow{3}{*}{$\equiv$} & \\
\hline JNO2 & Penganiayaan & & \multirow{2}{*}{ Edit } \\
\hline JNO3 & Penculikan & & \\
\hline JNO4 & Perkosaan & & \multirow{2}{*}{ (X) Hapus } \\
\hline JN05 & Sodomi & & \\
\hline
\end{tabular}

Gambar 6. Halaman menu lihat data jenis kasus

6. Halaman Hasil Analisa Double Exponential Smoothing

Halaman hasil analisa double exponential smoothing periode peramalan. Lebih jelasnya dapat dilihat pada Gambar 7.

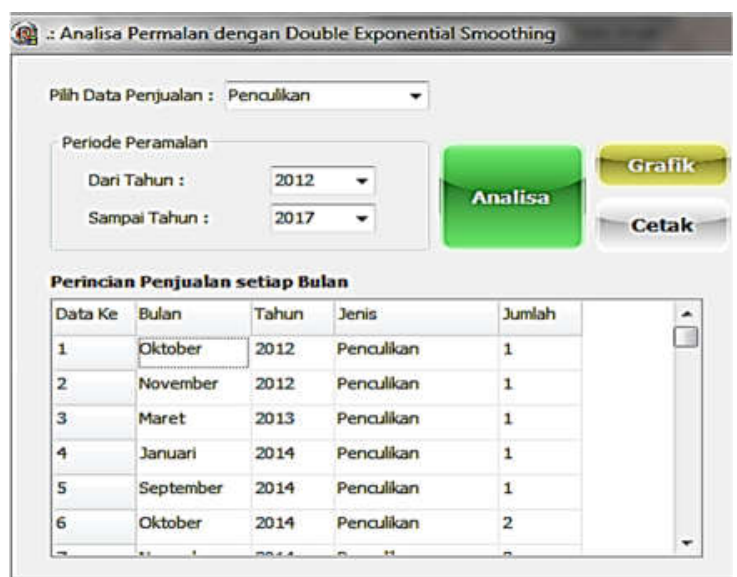

Gambar 7. Halaman hasil analisa

Halaman hasil analisa double exponential smoothing menampilkan id uji, alpha error, mape untuk nilai tingkat error margin dan hasil ramalan. Lebih jelasnya dapat dilihat pada Gambar 8.

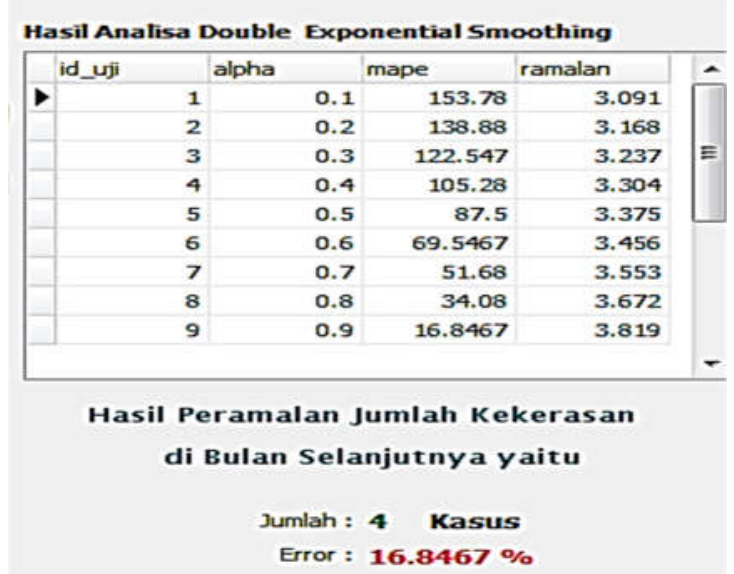

Gambar 8. Halaman hasil peramalan data kekerasan 


\section{KESIMPULAN}

Berdasarkan hasil pembahasan diatas, peneliti dapat mengambil beberapa kesimpulan antara lain sebagai berikut :

1. Dengan adanya analisa peramalan jumlah tindak kekerasan menggunakan metode double exponential smoothing pada peramalan kasus kekerasan pada anak maka kinerja dapat ditingkatkan lebih efektif dan efisien, sehingga dapat memprediksikan jumlah kekerasan dan daerah yang sering terjadi kekerasan.

2. Sistem peramalan ini menggunakan data kekerasan anak dari tahun 2013 sampai 2015, yang mana nantinya akan menghasilkan peramalan kekerasan anak tahun 2015.

3. Metode double exponential smoothing yang digunakan uktuk mengukur tingkat kesalahan peramalan adalah MSE dan RMSE. Nilai MSE adalah jadi tingkat menghitung nilai error untuk kesalahan terkecil dengan menggunakan RMSE.

4. Laporan yang dihasilkan dari sistem adalah laporan data kekerasan dari tiga jenis kekerasan yaitu Fisik, KDRT/Traumatic, dan Pelecehan Seksual, Selanjutnya MSE dan RMSE untuk menghitung nilai error terkecil.

\section{DAFTAR PUSTAKA}

[1] Baktiar, C. dkk. (2015). Pembuatan Sistem Peramalan Penjualan dengan Metode Weighted Moving Average dan Double Exponential Smoothing pada UD Y. Jurnal INFRA.

[2] Baroroh, A. (2013). Analisis Multivarlant dan Time Series dengan SPSS 21. Media Komputindo, Jakarta.

[3] Fachrurrazi, S. (2015). Peramalan Penjualan Obat Menggunakan Metode Single Exponential Smoothing pada Toko Obat Bintang Geurugok. Jurnal Techsi.

[4] Ginting, R. (2010). Sistem Produksi. Graha Ilmu, Yogyakarta.
[5] Prasetia, R. dkk. (2004). Teori dan Praktek Interfacing Port Paralel dan Port Serial Komputer dengan Visual Basic 6.0. Andi Publisher, Yogyakarta.

[6] Prihartanto, Y. L. (2011). Sistem Informasi Manajemen Agenda pada Badan Pelayanan Perijinan Terpadu Kabupaten Karanganyar. Journal Sentra Penelitian Engineering dan Edukasi (Speed).

[7] Priyadna, A. dkk. (2013). Pembuatan Sistem Informasi Nilai Akademik Berbasis SMS Gateway pada SMP Negeri 3 Pringkuku Pacitan. Jurnal Indonesian Journal on Networking and Security (IJNS).

[8] Rahmadayanti, R. dkk. (2015). Perbandingan Keakuratan Metode Autoregressive Integrated Moving Average (ARIMA) Dan Exponential Smoothing Pada Peramalan Penjualan Semen di PT.Sinar Abadi. Jurnal Rekursif.

[9] Simarta, J. dkk. (2010). Basis Data. Andi Publisher, Yogyakarta.

[10] .(2010). Peraturan Menteri Negara Pemberdayaan Perempuan dan Perlindungan Anak Republik Indonesia Nomor 05 Tahun 2010. Jakarta. 